\title{
ORFEU NEGRO EM CORES \\ mito e realismo no filme de Cacá Diegues
}

Lúcia Nagib

UNICAMP

\begin{abstract}
RES U M O
Orfeu, de 1999, dirigido por Carlos Diegues, um dos raros filmes atuais a falar do negro, retoma a tradicional apologia do afro-descendente por seus dotes musicais. Vinicius de Moraes, com sua peça Orfeu da Conceição, que deu base ao filme Orfeu negro (1959) e ao Orfeu de Diegues, pretendeu universalizar a música negra (e, portanto, a música brasileira), ampliando-a de seu reduto de classe baixa, ligada às orgias do carnaval e aos transes de terreiro, para a experiência sublime do amor absoluto. Para tanto, recorreu ao mito órfico do poder encantatório da música, recurso claramente anti-realista. Ao adaptar Vinicius, Diegues acrescentou uma dimensão realista à história, tentando não perder os aspectos míticos e trágicos. De fato, no filme, a utopia do paraíso negro desenvolve-se pari passu com a dura realidade da favela.
\end{abstract}

PALAVRAS - CHAVE

cinema brasileiro, negro, Orfeu

Com a decadência das esquerdas e a progressiva despolitização das artes a partir dos anos 80 , a temática negra, bandeira política freqüente no cinema brasileiro entre meados dos anos 50 e fins dos 70, praticamente abandonou as telas.

Orfeu, 1999, dirigido por Carlos Diegues, um dos raros filmes atuais a falar do negro, envereda pelo terreno ambivalente da apologia do afro-descendente por seus dotes musicais. Como se sabe, música e esporte são - no Brasil, como em outras ex-colônias de passado escravocrata - áreas em que o negro parece não sofrer discriminação, sendo mesmo particularmente bem sucedido. Embora esse fato deva-se a um talento extraordinário dos povos africanos para tais atividades, trata-se na verdade de uma segregação com um inegável elemento depreciativo, sempre apontado pelos próprios negros, já que tanto na música quanto no esporte supõe-se que o dom físico predomine sobre o intelectual. $\mathrm{O}$ ditado popular de que "samba (ou futebol) não se aprende na escola", ao mesmo tempo que exalta a vocação instintiva do artista ou esportista (ambos, no Brasil, predominantemente negros), de certa forma os exclui de atividades de caráter abstrato.

Não se questionam aqui as boas intenções de Carlos Diegues, que tem em seu currículo um histórico de militância pela causa negra. Iniciou a carreira de cineasta nos primórdios do Cinema Novo com Ganga Zumba (1964), filme sobre o escravo rebelde que liderou o Quilombo dos Palmares no século XVII, um drama histórico, com elenco 
exclusivamente negro, que alegorizava a problemática negra no presente brasileiro. Xica da Silva (1976) e Quilombo (1984) são outras incursões de Diegues no período da escravidão alegorizando situações de opressão e rebeldia no momento presente. Graças ao diretor, tornaram-se célebres atores como Zezé Motta, lançada em Xica da Silva e, desde então, diretora de uma organização não governamental que recruta e encontra colocação para atores negros. Em Orfeu, além da já tradicional presença de Zezé Motta, aqui como Conceição (a mãe do protagonista), e de outros atores negros célebres como Milton Gonçalves (Inácio, pai de Orfeu), Diegues apostou num novo talento, o jovem Toni Garrido, não por acaso um músico, membro da banda Cidade Negra.

Segundo explica o diretor, há muito ele desejava filmar uma nova versão da peça Orfeu da Conceição, de Vinicius de Moraes, que por assim dizer "corrigisse" a interpretação tão discutível da mesma peça feita pelo francês Marcel Camus em seu filme Orfeu do carnaval (título original: Orfeu negro), que internacionalizou a imagem de um Brasil negro e musical, conquistando a Palma de Ouro em Cannes e o Oscar de melhor filme estrangeiro em 1959. Diegues recorda:

Em 1959, já tendo realizado alguns curtas-metragens, metido na sopa primal de pessoas e idéias que daria no futuro Cinema Novo, vi com muita decepção o filme Orfeu negro, produção francesa dirigida por Marcel Camus, baseado em Orfeu da Conceição. Apesar de seu sincero encantamento pela paisagem humana e geográfica do Rio de Janeiro, apesar mesmo de um certo carinho pelo que estava sendo filmado, o filme enveredava por uma visão exótica e turística que traía o sentido da peça e passava muito longe de suas fundamentais qualidades. Me senti, na verdade, pessoalmente ofendido, e passei desde então a sonhar com o filme que é hoje o nosso Orfeu. ${ }^{1}$

Em 1980, Diegues chegou mesmo a apresentar seu projeto de Orfeu ao próprio Vinicius de Moraes, que imediatamente cedeu os direitos da peça e dispôs-se a escrever o roteiro junto com o cineasta. Na época, Diegues declarou: "Só posso [escrever o roteiro] com ele! Porque a situação dramática de Orfeu é arcaica, o que é bonito é o verso, a idéia de Orfeu, da arte vencedora, a idéia do amor, e uma compreensão de como é que isso se dá no Brasil". ${ }^{2}$ A morte do poeta em julho do mesmo ano interrompeu o projeto, que seria novamente retomado e abandonado por produtores americanos em 1991, para enfim realizar-se com uma concepção inteiramente nova e produtores brasileiros em 1998, sendo o filme lançado em 1999.

Ser fiel ao espírito da peça de Vinicius era, portanto, mandamento principal. E o espírito da peça, segundo as palavras de Vinicius por ocasião da estréia da primeira montagem do Orfeu da Conceição no Rio de Janeiro, em 1956, era "uma homenagem do seu autor e empresário, e de cada um dos elementos que a montaram, ao negro brasileiro, pelo muito que já deu ao Brasil mesmo dentro das condições mais precárias de existência”. ${ }^{3}$ Ao mesmo tempo, era preciso fugir ao exotismo de Camus, que, pretendendo retratar um negro livre em sua criatividade espontânea, na verdade o aprisionava no "gueto" da música.

\footnotetext{
${ }^{1}$ Extraído do press release de Orfeu.

${ }^{2}$ Extraído do press release de Orfeu.

${ }^{3}$ Moraes. Radar da batucada, p.49.
} 


\section{VINICIUS E O MITO}

Embora a música de origem africana tenha penetrado e transformado a música brasileira como um todo, permaneceu sempre caracterizada como uma arte popular e inculta. Vinicius, com sua peça, pretendeu universalizar a música negra (e, portanto, a música brasileira), ampliando-a de seu reduto de classe baixa, ligada às orgias do carnaval e aos transes de terreiro, para a experiência sublime do amor absoluto.

Para tanto, recorreu ao mito órfico do poder encantatório da música. Segundo a lenda grega, Orfeu, inventor da cítara, encantava homens, animais e toda a natureza com seu dom musical. Chamado pelos argonautas para marcar o ritmo de seus remos, livrou-os, com sua música, do canto irresistível e mortal das sereias, razão pela qual, segundo algumas versões da lenda, elas teriam se suicidado. De volta à Trácia, casou-se com Eurídice. Um dia, fugindo de Aristeu que queria possuí-la, Eurídice foi picada por uma cobra, vindo a falecer. Desesperado, Orfeu desceu aos infernos a sua procura, dominando com sua música Caronte, Cérbero e mesmo os deuses infernais. Hades, impressionado, concordou em devolver-lhe Eurídice, mas com a condição de que ela o seguisse e que Orfeu não olhasse para trás até atingirem a luz do sol. Ansioso para confirmar que não fora enganado, Orfeu virou-se para trás e perdeu a amada para sempre. Enciumadas ao vê-lo cantar inconformado a paixão perdida, as mulheres da Trácia o esquartejaram. Sua cabeça e sua lira foram atiradas ao rio e transportadas para a ilha de Lesbos, que se tornou desde então o centro da poesia lírica.

Vinicius narra a origem de sua idéia:

Foi em 1942, num jantar com meu amigo e escritor americano Waldo Frank, que surgiu o que se poderia chamar o embrião de onde nasceria, alguns meses mais tarde, a idéia de Orfeu da Conceição. Acompanhava eu, então, o autor de America Hispana em todas as incursões por favelas, macumbas, clubes e festejos negros no Rio, e me sentia particularmente impregnado do espírito da raça. Conversa vai, criou-se subitamente em nós, através de um processo por associação caótica, o sentimento de que todas aquelas celebrações e festividades a que vínhamos assistindo tinham alguma coisa a ver com a Grécia; como se o negro, o negro carioca no caso, fosse um grego em ganga - um grego ainda despojado de cultura e do culto apolíneo à beleza, mas não menos marcado pelo sentimento dionisíaco da vida. ${ }^{4}$

É uma atitude que, segundo as palavras de Robert Stam, segue "a tradição do primitivismo europeu e do movimento da negritude, que colocam a Grécia como razão e a África como emoção, como se a música afro-brasileira trouxesse uma dimensão dionisíaca a um tema apolíneo". 5

A equiparação ao mito grego seria portanto o modo de elevar a música negra a um estágio superior, em que os excessos da carne são redimidos pela pureza do espírito. Era, para tanto, fundamental que Orfeu fosse bom, "um ser quase divino, pela excelência de sua qualidade pessoal e artística”. ${ }^{6}$ A peça de Vinicius leva explicitamente seus personagens a transcenderem suas determincações sociais. Através do amor e da música, os habitantes negros de uma favela superam a pobreza e o isolamento causados sobretudo

${ }^{4}$ Moraes. Radar da batucada, p.47.

${ }^{5}$ STAm. Tropical multiculturalism, p.168.

${ }^{6}$ Moraes. Radar da batucada, p.48. 
pela cor. $\mathrm{O}$ intuito era transcender o real pela universalidade do mito. Para Vinicius, era importante que seu drama não transformasse "o mito de Orfeu numa tragédia realista". ${ }^{7}$ Explica ele:

Tudo o que fiz foi colocar nas mãos de um herói de favela, em lugar da lira helênica, o violão brasileiro, e submetê-lo ao sublime e trágico destino de seu homônimo grego - destino que o levou, através da integração total pela música, ao conhecimento do amor no seu mais alto e belo sentido e, pelo amor, às forças incontroláveis da paixão, à destruição eventual da harmonia em si mesma e no mundo em torno e, finalmente, à sua própria morte. ${ }^{8}$

O interesse de se localizar o drama no período do carnaval devia-se precisamente ao fato de ser este o momento em que "os negros se libertam de sua pobreza no luxo das fantasias compradas à custa de economias de um ano". ${ }^{9}$

Outra exigência anti-realista de Vinicius, igualmente destinada a universalizar o drama, referia-se à utilização de artistas exclusivamente negros. Justificava ele: "Me parece que seria atentar contra o seu espírito por assim dizer helênico nela colocar atores racialmente mesclados". ${ }^{10}$

O purismo de Vinicius se, por um lado, era uma exaltação sem precedentes dos afrodescendentes no teatro brasileiro, por outro, com sua recusa do realismo, oferecia o risco óbvio de acarretar interpretações edulcoradas como a de Marcel Camus. Aproveitando a ausência de contextualização no drama original, o filme de Camus reduziu a peça à sua caricatura, transformando a presença negra no Rio de Janeiro em puro exotismo: uma população pobre mas feliz, sensual mas ingênua, que não parece se preocupar com sua marginalidade social e dança o samba o dia inteiro, mesmo quando tem que subir o morro com latas d'água na cabeça. Stam observa, com humor, que o filme

oferece uma visão altamente idealizada da vida numa favela: espaçosa, com cabanas rústicas de colorido alegre, equipadas com cortinas coloridas, camas de metal e bichinhos de estimação, oferecendo as melhores vistas do Rio. De fato, o modo como a favela é tratada no filme por vezes se assemelha a um anúncio imobilário; todo mundo adoraria morar ali. ${ }^{11}$

No fundo, embora falsamente tomado como um dos iniciadores da nouvelle vague francesa, o filme de Camus é conservador, tanto em sua forma narrativa quanto na sugestão de que o negro encontra-se adaptado e feliz no morro, lugar ideal para seu modo de vida e para a criação de seu samba. Dois pontos de vista, portanto, diversos: o de Vinicius, criando um universo inteiramente negro onde o afro-descendente transcende sua condição e equipara-se aos deuses; e um outro, onde o negro enclausura-se numa felicidade idealizada e inofensiva à ordem vigente. O novo Orfeu parece ter procurado unir e superar essas duas visões, ao reinterpretar o mito grego e a situação do negro na favela.

Como bem observa Stam, a peça de Vinicius surgira num momento em que era moda atualizar mitos gregos, freqüentemente o do próprio Orfeu. Jean Cocteau vinha

\footnotetext{
${ }^{7}$ CAstello. Vinicius de Moraes - O poeta da paixão, p.182.

${ }^{8}$ Moraes. Radar da batucada, p.48.

${ }^{9}$ Moraes. Radar da batucada, p.48.

${ }^{10}$ Moraes. Radar da batucada, p.49.

${ }^{11}$ STAM. Tropical multiculturalism, p.174.
} 
criando sua trilogia órfica ao longo de três décadas: O sangue de um poeta (1930), Orfeu (1949) e O testamento de Orfeu (1959). Orfeu negro, título origial do filme de Camus, era como Jean-Paul Sartre chamara seu prefácio à Antologia da nova poesia negra e malgache de língua francesa, do senegalês Léopold Sédar Senghor, no fim dos anos 40 .

Essas influências européias no pensamento do poeta nem sempre foram bem vistas dentro da própria comunidade negra brasileira. Abdias Nascimento, um dos atores da primeira encenação da peça de Vinicius, chegou a fazer críticas ásperas a tal opção:

Atores brancos de rosto negro, Cristo negro, Orfeu negro: em última análise, todos conspiram no estupro histórico do meu povo. A cultura religiosa africana é rica e está viva em nossas comunidades religiosas por todo o Brasil. Não precisamos invocar a Grécia ou a Bíblia para nos elevarmos ao status de mitologia. Por outro lado, a Grécia e a Europa devem à África boa parte do que chamam de "civilização ocidental". ${ }^{2}$

É evidente que uma adaptação contemporânea da peça de Vinicius não poderia ignorar tais críticas, nem transpor literalmente seu purismo pioneiro. Assim, a atitude de Diegues, junto com seus vários co-roteiristas, foi no sentido de recuperar a dimensão realista sem perder a mítica e trágica. São dois níveis que caminham juntos ao longo do filme.

\section{A DIMENSÃO REALISTA}

De um lado, Orfeu reata com a mais forte tradição realista. Uma de suas seqüências inicias faz tomadas aéreas de um Rio de Janeiro deslumbrante e, a seguir, do assombroso amontoado de barracos de uma favela, encravada no coração da cidade, revelando de imediato o contraste de classes sociais. Trata-se de uma evidente homenagem à célebre abertura de Rio 40 graus (1956), no qual aliás a cidade é introduzida como name before the title, ou seja, o ator principal: "A cidade de São Sebastião do Rio de Janeiro em... Rio 40 graus".

A citação do filme de Nelson Pereira dos Santos, por sua vez, remete ao cinema neo-realista, que lhe deu base, e aos filmes de estilo documentário de Rossellini sobre cidades que aparecem como personagens - Roma, cidade aberta (1945) e Alemanha, ano zero (1947) - e colocam o contexto social como fator determinante do comportamento humano. A favela do novo Orfeu, adaptada às condições e à música contemporâneas, vai ser, neste primeiro momento, mostrada em planos picotados, em ritmo de videoclipe, acompanhando a batida rap — estilo de música negra (freqüentemente de protesto) que irá mesclar-se ao longo do filme ao samba-enredo, composto por Caetano Veloso, e às canções bossa-nova de Tom Jobim e Luís Bonfá, originalmente compostas para a peça de Vinicius e o filme de Camus.

Outro elemento de intenção realista é a variedade de detalhes destinados a recompor a história do negro no carnaval e na favela. Um policial que invade a favela encontra o compositor Orfeu e entoa para ele o refrão do samba-enredo que este compôs para o carnaval daquele ano: "Quando Hilário saiu/ Lá da Pedra do Sal/ Rei de Ouro surgiu/É carnaval”. Este refrão - em canção composta por Caetano por encomenda de Diegues - aponta as origens baianas do carnaval carioca.

Hilário Jovino Ferreira foi um dos milhares de baianos afro-descendentes, forros

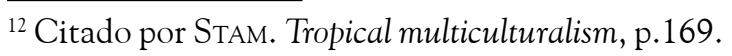


ou libertos, que migraram da Bahia para o Rio de Janeiro ao longo do século XIX em busca de trabalho. Concentravam-se eles de início no bairro da Saúde, perto do porto, onde eram acolhidos por seus conterrâneos até que se estabelecessem na vida. Levando consigo as tradições católicas e nagôs da Bahia, Hilário fundou "ranchos" que se transformariam nos blocos característicos do carnaval carioca. Eis como o próprio Hilário narra sua experiência no Rio:

Em 6 de janeiro de 1893, estava eu no botequim do Paraíso (...) em companhia de vários baianos que costumeiramente ali se reuniam, quando me lembrei da festa dos Três Reis Magos que na Bahia se comemorava naquele dia. (...) Propus então a fundação de um rancho. Passando a idéia em julgado, ali mesmo eu dei o nome de Rei de Ouro. Na mesma hora, no armarinho de um turco, fronteiro ao botequim, comprei meio metro de pano verde e meio de pano amarelo e fiz um estandarte no estilo da Bahia para os ensaios. ${ }^{13}$

Roberto Moura esclarece que o "rancho" era inicialmente proposto como a festa natalina cristã, caracterizada pela procissão dramática no dia de Reis, mas a forma dionisíaca com que o negro se apropriara das festas católicas "provocou protestos e interdições que têm como conseqüência o deslocamento das principais festas negras para o tempo desinibido do carnaval e sua definitiva profanização". ${ }^{14}$ Moura ressalta ainda a importância política dos ranchos:

Os ranchos, cortejos de músicos e dançarinos religiosos mas pândegos e democráticos, que já anteriormente apareciam na Bahia, lutariam carnavalescamente para impor a presença do negro e suas formas de organização e expressão nas ruas da capital da República. ${ }^{15}$

Caetano está, portanto, referindo-se às origens baianas ou mesmo africanas do carnaval, a partir de uma população concentrada na borda da cidade, população esta que a seguir daria início às primeiras favelas nos morros. Um dos primeiros deles, aliás, o morro da Conceição (que inspirou o nome Orfeu da Conceição, da peça de Vinicius).

Essa retrospectiva histórica, que se repete insistentemente no refrão do sambaenredo de Caetano, coloca o negro ao mesmo tempo nas origens do samba, do carnaval e do morro/favela. Não é apenas uma celebração da invenção do samba e do carnaval carioca, mas também a lembrança da escravidão, da migração do negro da Bahia pela falta de emprego, da marginalidade na nova cidade.

Que o refrão seja entoado pela primeira vez, no filme, por um policial que, com seus colegas, dá uma violenta batida no morro aponta para a situação nem um pouco paradisíaca em que os negros vivem até hoje com sua música. É dia de carnaval, a imprensa sobe o morro para entrevistar Orfeu — o compositor oficial da escola de Samba Unidos da Carioca - e então foguetes começam a explodir. Comemoração? Não, um aviso aos traficantes de que a polícia vem aí. De fato, logo o ruído dos rojões é substituído pelo de tiros, misturando-se a alegria do carnaval à tragédia cotidiana dos morros, com crianças morrendo de balas perdidas e policiais corruptos negociando com gangues do narcotráfico.

O metacinema também serve de álibi para outra inserção realista. Trata-se de um

\footnotetext{
${ }^{13}$ Ferreira citado por Moura. Tia Ciata e a Pequena África no Rio de Janeiro, p.88.

${ }^{14}$ Moura. Tia Ciata e a Pequena África no Rio de Janeiro, p.88.

${ }^{15}$ Moura. Tia Ciata e a Pequena África no Rio de Janeiro, p.89.
} 
breve insert de uma célebre cena da chanchada da Atlântida, Carnaval Atlântida (1952), em que Grande Otelo, travestido de grego, dança carnaval com Helena de Tróia. A cena é mostrada na televisão de uma sala onde moças da escola de samba Unidos da Carioca provam sua fantasia de carnaval. Esta citação permite uma breve digressão sobre o ingresso do negro no cinema brasileiro - que não deixa de ter sua relação com a história de Hilário Jovino.

O cinema teve ingresso precoce no Brasil. A primeira projeção de "cenas animadas" ocorreu em 8 de julho de 1896, no Rio de Janeiro, apenas seis meses após os irmãos Lumière promoverem, em Lyon, a sessão inaugural de cinema do mundo. Tal precocidade tecnológica contrastava com uma sociedade atrasada, que apenas oito anos antes libertara seus escravos.

Assim, enquanto imigrantes italianos preparavam-se para fazer as primeiras "tomadas de vista" que dariam início à produção de filmes no Brasil, os negros recémlibertos precipitavam-se para os poucos ramos de trabalho remunerado que lhes eram acessíveis. Além de serviços em portos, oficinas, fábricas e lojas, encontravam um campo especialmente fértil nos teatros populares, circos e cabarés.

Configura-se, assim, o primeiro caminho que dará ao ex-escravo acesso ao cinema: o espetáculo. A comédia circense, a música e a dança constituirão, desde o início até os nossos dias, a área em que o ator negro encontrará abrigo, mesmo que freqüentemente folclorizante e limitado por discriminações e proibições. Não custa lembrar que os raros negros que algum dia tiveram a chance de dirigir filmes no Brasil começaram como atores (alguns deles, vindos diretamente da música). É o caso de Antônio Pitanga, Zózimo Bulbul, Waldyr Onofre e mesmo Haroldo Costa (que começou como músico), o primeiro a interpretar Orfeu no palco. (Trabalho supostamente mais intelectualizado e com maior concentração de poder que o do ator, a direção de filmes permanece sendo terreno praticamente interdito ao negro no Brasil. No presente momento, não há, de meu conhecimento, um negro sequer dirigindo um longa-metragem no país.)

O cinema de ficção dos primeiros tempos conta, desde logo, no Brasil, com a presença negra proveniente das artes de espetáculo. Destaque da primeira década deste século é Benjamin de Oliveira, palhaço do circo Spinelli, que gozava na época de enorme popularidade. Primeiro ator negro do cinema brasileiro, Oliveira celebrizou-se por sua interpretação do personagem Peri, em Os guaranis, filmagem realizada em 1908, por Antônio Leal, de um espetáculo protagonizado pelo próprio ator no circo.

Outro ator negro, Eduardo das Neves, este músico e mímico, foi figura freqüente nas telas no começo do século. O cinema no Rio, nessa virada de século, misturava-se com teatros de revista e vaudevilles, cafés-concerto, cafés-dançantes etc., e é desse mesmo caldo, comandado por Hilário Jovino e os bailes de Tia Ciata, que surge Eduardo das Neves, o palhaço negro que se torna um dos primeiros hits dos espetáculos no Rio. ${ }^{16}$

Os anos 30 abrem uma nova perspectiva para o negro com o advento do som no cinema. A música de origem africana — o samba e os ritmos carnavalescos — já era ingrediente dominante no rádio, no teatro de revista, nos shows de cassinos. A combinação da experiência musical nesses três campos está na origem das pequenas produtoras cinematográficas que surgem no Rio de Janeiro em meados dos anos 30. A

${ }^{16}$ Cf. Moura. Tia Ciata e a Pequena África no Rio de Janeiro, p.78. 
Cinédia, a Brasil Vita Filmes e a Waldow Film são precursoras da Atlântida, que, ao longo dos anos 40 e 50, produziria o gênero mais popular jamais feito no cinema brasileiro: a chanchada.

Comédias musicais que parodiavam o cinema hollywoodiano, aproveitando-se das canções de sucesso do rádio e do carnaval, e usando os atores do teatro de revista, as chanchadas celebrizaram a dupla cômica Grande Otelo e Oscarito. Grande Otelo, na verdade, já era há anos ator de sucesso em todo o Brasil. Baixinho, de lábios grossos e olhos saltados, tinha tudo para se transformar na caricatura do negro. Venceu todas as barreiras, porém, graças a um talento múltiplo e extraordinário, como ator, mímico, cantor, compositor e dançarino, dotes estes que se revelaram desde a tenra infância.

Pois bem, o Grande Otelo cômico da chanchada citada em Orfeu é também o talentoso compositor de morro de Rio Zona Norte (1957) (outro filme homenageado por Diegues), personagem órfico que tem suas canções roubadas e assinadas por brancos dos bairros nobres do Rio.

Esta retrospectiva histórica, feita a partir da canção de Caetano Veloso e de citações dos filmes seminais de Nelson Pereira do Santos e da chanchada, reconstrói a linhagem de sofrimento e luta do Orfeu atual através de seus antepassados. Sua felicidade presente custou um preço alto, deixando de ser portanto aquele estado idílico permanente dos personagens de Camus.

De origem humilde, o novo Orfeu é porém um negro que se deu bem. Um compositor que enriqueceu e que, em lugar de ter suas canções roubadas como outrora o personagem de Grande Otelo, tem seu nome amplamente reconhecido por todos os setores da sociedade. Longe de ser um analfabeto, tem quase a cara de um intelectual, com os óculos que coloca quando vai trabalhar em seu computador portátil e seu celular que não pára de tocar. É ainda um negro que convive com os brancos da favela em pé de igualdade. Aliás, a introdução de personagens brancos — que contraria o desejo original de Vinicius - mais uma vez confirma a intenção realista de Diegues, ao quebrar a uniformidade idealista do mundo helênico.

Tanto quanto o herói, os demais personagens do novo Orfeu são de um modo geral realistas por estarem a serviço de um painel da contemporaneidade do morro carioca. E expressam-se de modo correspondente, desta vez seguindo à risca a recomendação de Vinicius de Moraes nesse sentido: "tratando-se de uma peça onde a gíria popular representa um papel muito importante, e como a linguagem do povo é extremamente mutável, em caso de representação deve ela ser adaptada às suas novas condições". ${ }^{17}$

Graças à colaboração do co-roteirista Paulo Lins - escritor negro, autor do excelente Cidade de Deus, retrato impressionante de uma favela carioca —, os diálogos são de um realismo detalhista na utilização da gíria dos traficantes do morro, dos policiais, dos moleques-artistas, dos evangelistas, dos sambistas e de toda a variegada população de uma favela.

Longe de ser o reduto da bondade simples e humilde, como retratada em Rio 40 graus, Rio Zona Norte ou mesmo no Orfeu negro, a população do morro é complexa. A violência é o pão cotidiano: um rapaz é exterminado, como mero divertimento, pela

${ }^{17}$ Moraes. Radar da batucada, p.54. 
gangue da droga apenas por ter tido sexo consentido com uma menina. Fofoca e ciúme são a tônica entre as mulheres. Os preconceitos abundam: "Detesto paraíba", diz o policial Pacheco, frase que vem direto de Cidade de Deus, referindo-se sobretudo à rivalidade entre negros e nordestinos nas favelas.

Segundo Diegues, a favela de Orfeu corresponde à terceira fase de seu desenvolvimento histórico: não mais a favela romântica e ingênua, povoada de personagens bons de Orfeu negro ou Rio 40 graus, não mais a favela infernal do inchaço urbano e das migrações desordenadas, mas a favela da luta pela afirmação, pelo orgulho de ser favelado, mesmo convivendo com todas as suas adversidades.

\section{A DIMENSÃO MÍTICA}

A trama de Orfeu desenvolve-se numa favela cenográfica, construída de modo que nenhum de seus detalhes sórdidos ou pitorescos, encontráveis na realidade, fossem esquecidos. Lá estão as escadarias labirínticas, os imundos depósitos de lixo, e também a rádio pirata com alto-falantes espalhados por todo canto que noticiam, na linguagem flexível e inventiva do morro e em ritmo de rap/funk, os acontecimentos da favela. Lá estão ainda os botecos onde se reúnem os sambistas (e aqui o filme não deixa de homenagear algumas celebridades como Nelson Sargento) e os pequenos templos evangélicos para os que querem fugir da bebida e dos "pecados da carne".

Neste cenário que se pretende em tudo fiel ao real, são introduzidos os dois personagens que se despregam de seus laços reais para se tornar em tudo fictícios: Orfeu e Eurídice. A bela cena erótica que inicia o filme, em que Orfeu faz amor com sua namorada Mira (dois atores negros belíssimos, Toni Garrido e Isabel Filardis), coloca desde logo a dimensão carnal que Orfeu quer superar, transcender: sua única noite de sexo com a até então virgem Eurídice não será mostrada, indicando uma outra qualidade de amor, um amor sublime, espiritual. Como no filme de Camus, as crianças o chamam para que, com sua música, faça o sol nascer. O nome "Orfeu" parecendo-lhes estranho, elas o chamam de "Feu", sendo sempre corrigidas pelo músico. "Eurídice" também soará estranho às crianças: uma delas pixará o muro do barraco da moça com o trocadilho "Euridoce".

Eles de fato não pertencem àquele universo. Eurídice chega ao Rio de avião, como um anjo caído dos céus. ${ }^{18}$ No filme politicamente correto de Diegues, ela não é negra, nem branca, mas uma índia vinda do Acre (apesar de a atriz Patrícia França ser uma típica mistura negra e portuguesa), um ser absurdo na favela, quase sobrenatural.

Fica claro também, ao longo do filme, que Orfeu não pertence mais à realidade do morro. Os próprios policiais perguntam-lhe por que, sendo tão bem-sucedido, ainda continua lá. Orfeu, irrealista, utópico, destinado ao fim trágico, acredita que a favela pode transformar-se num lugar bom. Ingênuo por acreditar que suas próprias boas intenções possam superar as determinações sociais, desafia Lucinho, o chefe do narcotráfico, a abandonar o morro com sua gangue. Perde a aposta, é claro. Eurídice é assassinada por Lucinho - que nutre uma espécie de amor homossexual por Orfeu — e este é morto por

\footnotetext{
${ }^{18}$ Este detalhe foi introduzido, segundo o release do filme, como uma homenagem a Godard, que, ao comentar o filme de Camus, disse que Eurídice não deveria ter chegado ao Rio de barco, mas de avião, para que visse a paisagem mais linda do mundo.
} 
suas ex-amantes, depois de recuperar o corpo da amada no despenhadeiro da favela, o "inferno" real onde se acumulam cadáveres, carcaças de carros e lixo de toda espécie.

"A felicidade do pobre parece / a grande ilusão do carnaval": esta continua sendo a verdade do morro, nos versos célebres da canção "A felicidade", de Tom e Vinicius, no filme singelamente entoada pela filha adolescente de Tom Jobim, Maria Luiza Jobim.

A utopia de Orfeu, sua transcendência mítica, na verdade contamina toda a construção realista do filme. As paisagens deslumbrantes do Rio, o majestoso desfile liderado pelo carnavalesco Joãosinho Trinta (que, coincidentemente, em 1998 idealizou para sua escola, a Viradouro de Niterói, o tema "Orfeu"), a própria beleza apolínea do jovem Garrido apontam para um paraíso negro onde só o amor existe.

Porém, a morte de Orfeu, no momento em que é anunciada a vitória de sua escola no carnaval, devolve a população da favela à realidade. $O$ menino Maicol (pseudônimo que adotou em homenagem a Michael Jackson) e Inácio (o pai de Orfeu, antigo sambista e atual pastor evangélico), aquele com seus gritos ritmados, e este com um apito, inventam uma nova canção, que mostra a verdadeira origem da música na favela. São mais uma vez os versos de Vinicius que voltam a valer: "Tristeza não tem fim / felicidade sim".

\begin{abstract}
A B STRACT
Carlos Diegues's Orpheus, 1999, one of the few contemporary films to focus on blacks, makes the traditional panegyric of the African descendents for their musical skills. Vinicius de Moraes, with his play Orfeu da Conceição, on which Black Orpheus (1959) and Diegues's Orpheus were based, intended to universalise black music (therefore Brazilian music), upgrading it from its low class niche associated with carnival orgies and voodoo trances, to the sublime experience of absolute love. To that end, he resorted to the enchanting power of music contained in the Orphic myth, in a clearly anti-realistic attitude. When he adapted de Moraes, Diegues added a realistic dimension to the story, while trying to keep the mythic and tragic ones. Indeed, in the film, the utopia of black paradise merges with the hard reality of Rio slums.
\end{abstract}

KEY-WORDS

Brazilian cinema, black, Orpheus

\title{
REFERÊNCIAS BIBLIOGRÁFICAS
}

Moraes, Vinicius de. Teatro em versos. Org. Carlos Augusto Calil. São Paulo: Companhia das Letras.

STAM, Robert. Tropical multiculturalism; a comparative history of race in Brazilian cinema $\mathbb{E}$ culture. Durham, Londres: Duke University Press, 1997.

Castello, José. Vinicius de Moraes - O poeta da paixão. São Paulo: Companhia das Letras.

MourA, Roberto. Tia Ciata e a Pequena África no Rio de Janeiro. Rio de Janeiro: Biblioteca Carioca, 1995. 